\title{
Effect of starvation and re-feeding on the digestive system of Penaeus japonicus Spence Bate, 1888
}

\author{
YICHAO DONG ${ }^{1,2}$, YIBING LIU ${ }^{3}$, ZHENHUA MA ${ }^{4}$, XIA, LI ${ }^{1}$ AND LIXIN WU ${ }^{1}$ \\ ${ }^{1}$ Shangdong Vocational College of Science and Technology, Weifang, China \\ ${ }^{2}$ Key Laboratory of Mariculture Biotechnology Agriculture Ministry, P. R. China, Dalian Ocean University \\ Dalian, China \\ ${ }^{3}$ Liaoning Ocean and Fisheries Sciences Research Institute, Dalian, China \\ ${ }^{4}$ Tropical Fishery Research and Development Center, South China Sea Fisheries Research Institute \\ Chinese Academy of Fishery Sciences, Sanya, China \\ e-mail: zhenhua.ma@hotmail.com
}

\begin{abstract}
This study investigated the effects of starvation and refeeding on the histological features of stomach and intestine in Penaeus japonicus Spence Bate, 1888. Five treatment groups of $P$. japonicus were initially starved for 0, 5, 10, 15 and 25 days (designated as $\mathrm{S}_{0}, \mathrm{~S}_{5}, \mathrm{~S}_{10}, \mathrm{~S}_{15}$ and $\mathrm{S}_{25}$, respectively) and subsequently fed for 15 days. The effect on digestive system was evaluated using epithelial cell height in stomach and intestine as the assessment criteria and significant decrease in epithelial cell height was considered as damage due to starvation. With prolonged starvation period, the structure of stomach and intestine were found compromised. In the 5 days starvation group $\left(\mathrm{S}_{5}\right)$, the damage of the digestive system was not significant, whereas the damages became significant after 25 days starvation $\left(\mathrm{S}_{25}\right)$. In the damaged digestive system of shrimp, the boundary disappeared and the cells were found disassembled. The lumen of hepatic tubule in midgut gland enlarged, the number of the R cells decreased, and the cells were found disassembled. After refeeding, the structures in the stomach, intestine and midgut gland recovered, almost similar to the control group except in the 25 days starvation group. Results from the present study provide practical guidelines for feeding pattern during culture of P. japonicus.
\end{abstract}

Keywords: Digestive organ, Histology, Penaeus japonicus, Refeeding, Starvation

In shrimps during development, alternative episodes of feeding and fasting occur in terms of moulting which results in growth (Sanchez-Paz et al., 2006; Sacristan et al., 2016). Increase in body size at each moulting could last days or weeks along with morphological, physiological and behavioural alternations (Dall et al., 1990). During moulting, feeding stops completely and they feed again during post-moult until the shrimp has an exoskeleton rigid enough to support the weight and handle food (Phlippen et al., 2000). Therefore, understanding the structural changes of the digestive system during starvation and refeeding would be beneficial for providing information for management of shrimp aquaculture. Penaeus japonicus Spence Bate, 1888 is an important shrimp species in China and little study has been done on the effects of starvation and refeeding on the digestive organs of the species.

The same cohort of $P$. japonicus was collected from a commercial farm and transported in a live-holding tank to the experimental facility at Dalian Ocean University, Dalian, China. During acclimation, the shrimps were fed daily to satiation level with fresh clamworm until the start of the experiment. A total of 90 juveniles (average weight $13.51 \pm 1.30 \mathrm{~g}$ ) were placed in a $12 \mathrm{t}$ cement tank containing filtered natural seawater (temperature $19-21^{\circ} \mathrm{C}$; salinity $31 \%$ ). Seawater was changed $2 / 3^{\text {rd }}$ daily. After 5 days acclimation, the shrimps were randomly divided into 5 groups (having 3 replicates each) and food deprivation experiment was conducted in fifteen 5001 fiber glass tanks. All the rearing protocol was same as described for the acclimation period. Normal feeding group served as control $\left(\mathrm{S}_{0}\right)$ and the other four groups were subjected to food deprivation for 5 days $\left(\mathrm{S}_{5}\right), 10$ days $\left(\mathrm{S}_{10}\right)$, 15 days $\left(\mathrm{S}_{15}\right)$ and 25 days $\left(\mathrm{S}_{25}\right)$ duration. After starvation period, the shrimps were fed normally for 15 days. From each treatment group, three shrimps each were randomly sampled before and after starvation, as well as on 2, 5, 10 and 15 days of refeeding. Individual body weights of the sampled shrimps were ascertained and then the shrimps were dissected to estimate midgut gland (hepatopancreas) weights. Tissue samples from stomach, gut and midgut gland were fixed in Bouin's fixative and processed routinely for histology (Liu and Li, 2012). Sections (5 $\mu \mathrm{m})$ were cut using a microtome and stained with Hematoxylin 
and Eosin. Stained sections were examined under 100X magnification in an Olympus microscope. Images were scanned with microscope-mounted digital camera and examined on an image analyser.

In control group $\left(\mathrm{S}_{0}\right)$ without food deprivation, the weight of $P$. japonicus increased significantly from $13.51 \pm 1.30$ to $15.01 \pm 1.42 \quad(\mathrm{p}<0.05)$. In comparison with control group, weights in the food deprived groups decreased significantly $(\mathrm{p}<0.05)$. After refeeding, the weights in $\mathrm{S}_{5}$ and $\mathrm{S}_{10}$ were similar to the control, whereas the weights in longer food deprived groups $\left(\mathrm{S}_{15}\right.$ and $\left.\mathrm{S}_{25}\right)$ were significantly lower even after refeeding $(p<0.05$, Table 1).

Table 1. Comparison of weight changes of P. japonius after starvation and refeeding (Mean $\pm \mathrm{SD}$ )

\begin{tabular}{lll}
\hline Groups & After starvation $(\mathrm{g})$ & After refeeding $(\mathrm{g})$ \\
\hline $\mathrm{S}_{0}$ & $13.51 \pm 1.30^{\mathrm{A}, \mathrm{b}}$ & $15.01 \pm 1.42^{\mathrm{A}^{\prime}, \mathrm{a}}$ \\
$\mathrm{S}_{5}$ & $12.22 \pm 1.97^{\mathrm{B}, \mathrm{b}^{\prime}}$ & $15.07 \pm 2.08^{\mathrm{A}^{\prime}, \mathrm{a}^{\prime}}$ \\
$\mathrm{S}_{10}$ & $11.39 \pm 1.29^{\mathrm{B}, \mathrm{b}^{\prime \prime}}$ & $14.61 \pm 2.11^{\mathrm{A}^{\prime}, \mathrm{a}^{\prime \prime}}$ \\
$\mathrm{S}_{15}$ & $11.26 \pm 2.06^{\mathrm{B}, \mathrm{a}^{\prime \prime \prime}}$ & $13.44 \pm 1.73^{\mathrm{B}^{\prime}, \mathrm{a}^{\prime \prime \prime}}$ \\
$\mathrm{S}_{25}$ & $10.68 \pm 1.10^{\mathrm{B}, \mathrm{a}^{\mathrm{a} \prime \prime}}$ & $13.28 \pm 1.31^{\mathrm{B}^{\prime}, \mathrm{a}^{\prime \prime \prime \prime}}$ \\
\hline
\end{tabular}

Values bearing different capital letters in each treatment group indicate significant difference $(\mathrm{p}<0.05)$. Values bearing different lowercase letters in each period indicate significant difference $(p<0.05)$

In comparison with control group, the hepatosomatic index (HSI) [(hepatopancreas weight/whole body weight) $\mathrm{x}$ 100)] in all the food deprived groups decreased significantly $(\mathrm{p}<0.05)$ (Table 2$)$. However, after 2 days refeeding, $\mathrm{HSI}$ in $\mathrm{S}_{5}$ and $\mathrm{S}_{10}$ groups recovered with no significant difference in comparison with control group ( $p>0.05$ ). In $\mathrm{S}_{15}$ group, HSI was similar to control shrimps after refeeding for 10 days, whereas HSI in $\mathrm{S}_{25}$ group was still significantly lower than that in control group $(\mathrm{p}<0.05)$.

In $\mathrm{S}_{5}$ group, the volume of gut did not change and no faeces were observed. In contrast, in $\mathrm{S}_{10}, \mathrm{~S}_{15}$ and $\mathrm{S}_{25}$ groups, the volume of gut significantly decreased and the colour faded along with the intestinal wall turning transparent. After refeeding till the end of the experiment, the gut volume in $\mathrm{S}_{10}$ and $\mathrm{S}_{15}$ groups gradually increased and became full, with deepening of colour. On the contrary, the gut volume in $\mathrm{S}_{25}$ group was still lower in comparison with control group, whereas the intestine was transparent similar to control.

The gastric epithelium of the control group showed neatly arranged monolayer columnar cells. The cell boundary was clear and connective tissue was found as thin fibrous and distributed evenly (Fig. 1a). After 5 days of food deprivation, the height of epithelial cells were found decreased with the connective tissue loosely placed (Fig. 1b). At 10 days of food deprivation, height of the gastric epithelial cells decreased forming a gap between epithelium and exoskeleton and damaged connective tissue fibres were visible (Fig. 1c). After 15 days of starvation, the gap between epithelial cells and exoskeleton increased and the connective tissue was observed to be damaged and distributed unevenly (Fig. 1d). After 25 days of food deprivation, the epithelium was found thin with uneven distribution. The boundaries of cells were unclear and some fell off. Connective tissue was found severely damaged, causing large gaps and found distributed unevenly (Fig. 1e).

After refeeding for 10 days, the structure in 5 days starvation treatment recovered, similar to control. The epithelial cells increased after 5 days refeeding and continually increased upon 10 days refeeding in $\mathrm{S}_{10}$ group. Moreover, after 10 days refeeding, the epithelial cells were found arranged evenly and the connective tissue was loose, whereas the reticulum tissue was not clear (Fig. 1f). After 15 days refeeding, there was no significant difference in the height of epithelial cells in comparison with control and the fibres were distributed evenly in the connective tissue (Fig. 1g). In the $\mathrm{S}_{15}$ group, the epithelial cells were clear, but the arrangement was uneven and no obvious alterations in the connective tissue was observed after 2 days refeeding (Fig. 1h). After 5 days refeeding, the height of epithelial cells increased and the connective tissue was distributed evenly (Fig. 1i) in shrimps from $\mathrm{S}_{15}$ group. There was no significant difference in the height of cells and the fibre of connective tissue was distributed

Table 2. Hepato-somatic index (HSI) of P. japonicus after refeeding (Mean $\pm \mathrm{SD}$ )

\begin{tabular}{llllll}
\hline \multirow{2}{*}{ Group } & \multicolumn{5}{c}{ Days after refeeding } \\
\cline { 2 - 6 } & 0 & 2 & 5 & 10 & 15 \\
\hline $\mathrm{S}_{0}$ & $4.24 \pm 0.63 \mathrm{~A}, \mathrm{~b}$ & $4.29 \pm 0.54 \mathrm{~A}^{\prime}, \mathrm{b}$ & $4.64 \pm 0.51 \mathrm{~A}^{\prime \prime}, \mathrm{ab}$ & $4.72 \pm 0.42 \mathrm{~A}^{\prime \prime \prime}, \mathrm{a}$ & $4.87 \pm 0.45 \mathrm{~A}^{\prime \prime \prime \prime}, \mathrm{a}$ \\
$\mathrm{S}_{5}$ & $3.44 \pm 0.62 \mathrm{~B}, \mathrm{c}^{\prime}$ & $4.30 \pm 0.57 \mathrm{~A}^{\prime}, \mathrm{b}^{\prime} \mathrm{c}^{\prime}$ & $4.80 \pm 0.53 \mathrm{~A}^{\prime \prime}, \mathrm{a}^{\prime} \mathrm{b}^{\prime}$ & $4.92 \pm 0.59 \mathrm{~A}^{\prime \prime \prime}, \mathrm{a}^{\prime}$ & $4.99 \pm 0.54 \mathrm{~A}^{\prime \prime \prime}, \mathrm{a}^{\prime}$ \\
$\mathrm{S}_{10}$ & $2.88 \pm 0.45 \mathrm{BC}, \mathrm{c}^{\prime \prime}$ & $3.88 \pm 0.52 \mathrm{~A}^{\prime} \mathrm{B}^{\prime}, \mathrm{b}^{\prime \prime}$ & $4.37 \pm 0.73 \mathrm{~A}^{\prime \prime} \mathrm{B}^{\prime \prime}, \mathrm{a}^{\prime \prime} \mathrm{b}^{\prime \prime}$ & $4.62 \pm 0.45 \mathrm{~A}^{\prime \prime \prime} \mathrm{B}^{\prime \prime \prime}, \mathrm{a}^{\prime \prime}$ & $4.85 \pm 0.47 \mathrm{~A}^{\prime \prime \prime \prime}, \mathrm{a}^{\prime \prime}$ \\
$\mathrm{S}_{15}$ & $2.62 \pm 0.46 \mathrm{BC}, \mathrm{d}^{\prime \prime \prime}$ & $3.41 \pm 0.52 \mathrm{~B}^{\prime} \mathrm{C}^{\prime}, \mathrm{c}^{\prime \prime \prime}$ & $4.00 \pm 0.42 \mathrm{~B}^{\prime \prime} \mathrm{C}^{\prime \prime}, \mathrm{b}^{\prime \prime \prime} \mathrm{c}^{\prime \prime \prime}$ & $4.55 \pm 0.48 \mathrm{~A}^{\prime \prime \prime} \mathrm{B}^{\prime \prime \prime}, \mathrm{a}^{\prime \prime \prime} \mathrm{b}^{\prime \prime \prime}$ & $4.81 \pm 0.27 \mathrm{~A}^{\prime \prime \prime}, \mathrm{a}^{\prime \prime \prime}$ \\
$\mathrm{S}_{25}$ & $2.40 \pm 0.36 \mathrm{C}, \mathrm{c}^{\prime \prime \prime}$ & $2.96 \pm 0.46 \mathrm{C}^{\prime}, \mathrm{b}^{\prime \prime \prime} \mathrm{c}^{\prime \prime \prime}$ & $3.81 \pm 0.53 \mathrm{C}^{\prime \prime}, \mathrm{b}^{\prime \prime \prime \prime}$ & $4.48 \pm 0.18 \mathrm{~B}^{\prime \prime \prime}, \mathrm{a}^{\prime \prime \prime \prime}$ & $4.64 \pm 0.27 \mathrm{~B}^{\prime \prime \prime \prime}, \mathrm{a}^{\prime \prime \prime \prime}$
\end{tabular}

Values bearing different capital letters in each treatment group indicate significant difference $(\mathrm{p}<0.05)$

Values bearing different lowercase letters in each period indicate significant difference $(p<0.05)$ 


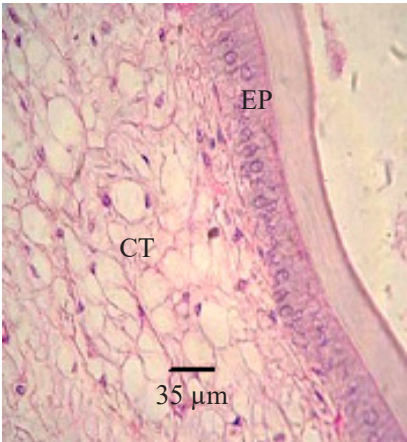

(a)

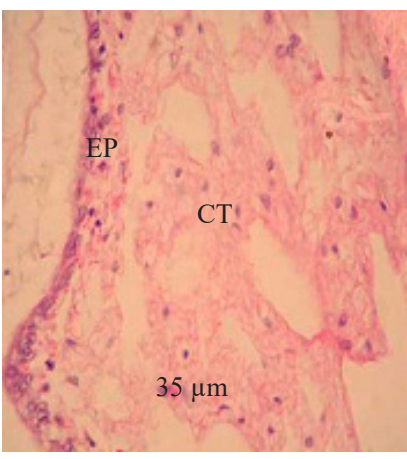

(e)

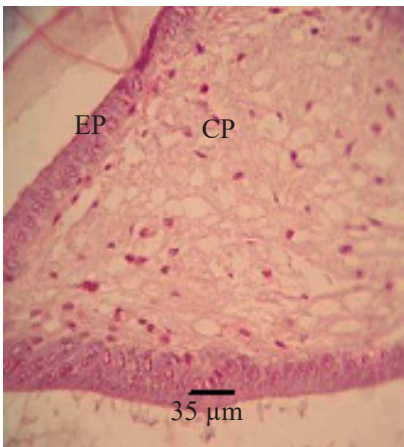

(i)

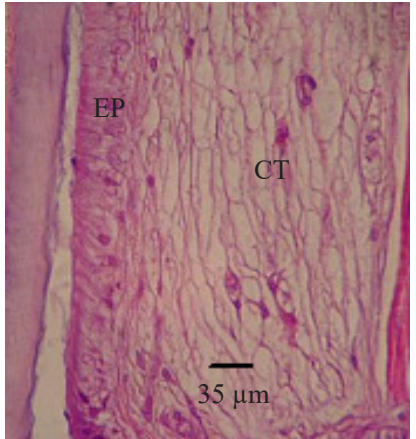

(b)

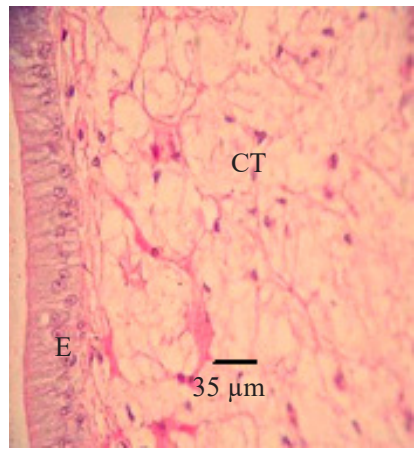

(f)

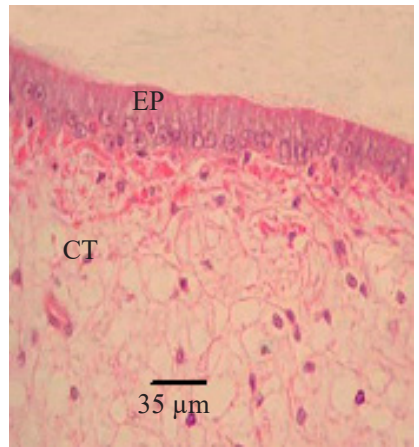

(j)

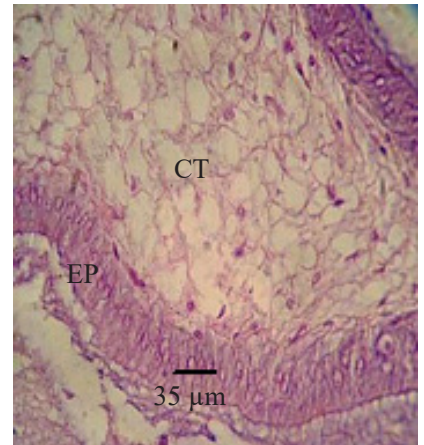

(c)

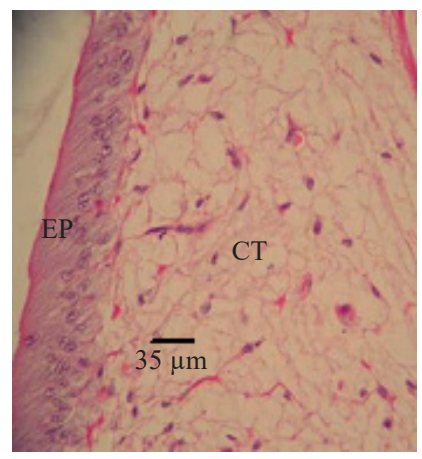

$(\mathrm{g})$

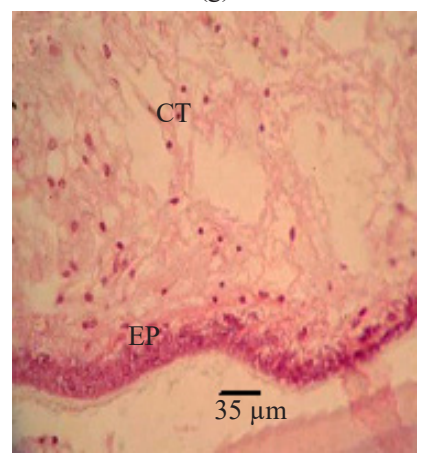

$(\mathrm{k})$

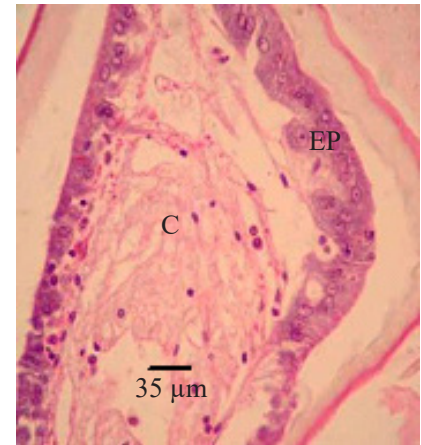

(d)

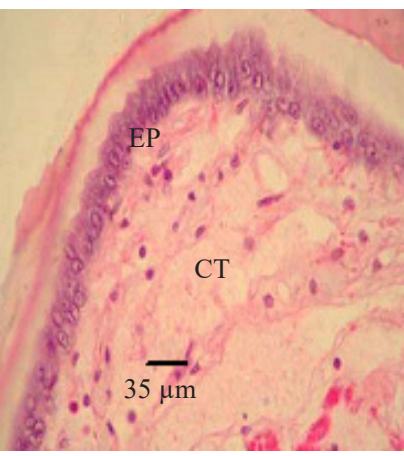

(h)

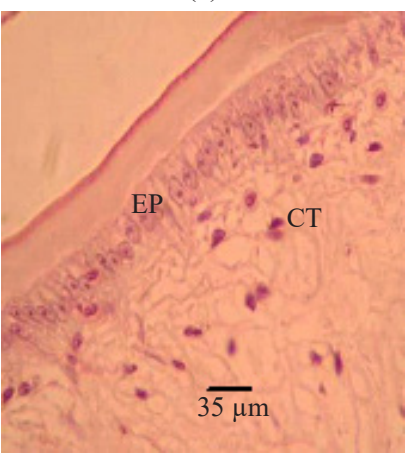

(1)

Fig. 1. Photomicrographs showing histological features in the stomach of control and starved P. japonicus

(a): Stomach section of control group $\left(\mathrm{S}_{0}\right)$ showing normal histological structure; (b): Compacted connective tissue in $\mathrm{S}_{5}$ group after 5 days of starvation; (c): Connective tissue with shattered fibres in $\mathrm{S}_{10}$ group after 10 days of starvation; (d): Connective tissue showing vaculation and damaged fibres in $\mathrm{S}_{15}$ group after 15 days starvation; (e): Hazy epithelial cell boundary with uneven distribution of connective tissue in $\mathrm{S}_{25}$ group after 25 days starvation period; (f): Loose connective tissue in $\mathrm{S}_{10}$ group after 10 days refeeding; (g): Histological structure of stomach in $\mathrm{S}_{10}$ group after refeeding for 15 days resembling that of control; (h): Epithelial cells distributed unevenly in $\mathrm{S}_{15}$ group after 2 days refeeding; (i): Height of the epithelial cells increased in $\mathrm{S}_{15}$ group after refeeding for 5 days; (j): Structure of stomach similar to control group after refeeding for 15 days in $\mathrm{S}_{15}$ group; (k): Unclear epithelial cells arranged unevenly in $\mathrm{S}_{25}$ group after refeeding for 2 days; (l): Connective tissue comparatively compacted in $\mathrm{S}_{25}$ group after refeeding for 15 days. CT: Connective tissue; EP: Epithelial cells

evenly after refeeding for 15 days (Fig. 1j). In $\mathrm{S}_{25}$ group, the epithelial cells were not clear with uneven arrangement and there was a large gap between connective tissues after refeeding for 2 days (Fig. 1k). After refeeding for 5 days, the height of the epithelial cells increased and the cells were clear and arranged evenly. Even after refeeding for 15 days, the height of the epithelial cells did not reach the level as in the control group, but the connective tissues were compact (Fig. 1-1).
In the control group, the intestinal walls comprised epithelium, membrane propria, muscle layer and chorion from inside to outside. The epithelial cells consist of simple columnar cells arranged evenly. Muscle layer consisted of circular and longitudinal muscles. Connective tissue in the chorion was thicker and had connective tissue cells with abundant blood vessels (Fig. 2a). After food deprivation, the gut was found compromised to certain extent depending on the duration of the food deprivation. Height of epithelial cells decreased after 5 days food 
deprivation (Fig. 2b). Further, the membrane propria was found attenuated after 10 days food deprivation (Fig. 2c). After 15 days of food deprivation, the epithelial cells were unevenly arranged and cells separated. Sloughed off cells were found in the gut cavity. At the same time, circular muscle layer was fragmented and the connective tissues between muscle cells became loose (Fig. 2d). After 25 days food deprivation, the boundary of epithelial cells was diffused, showing necrotic nuclei, circular muscle

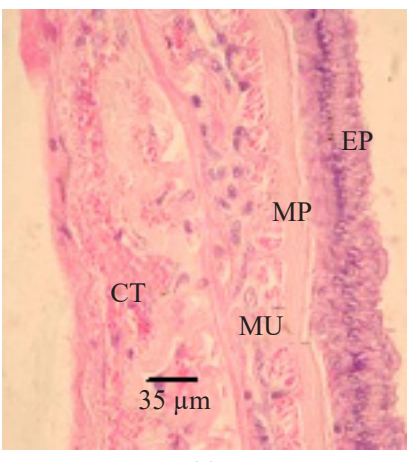

(a)

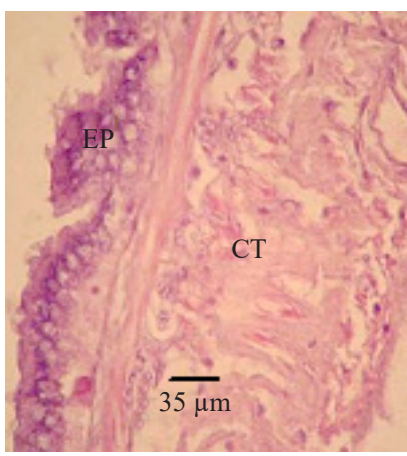

(e)

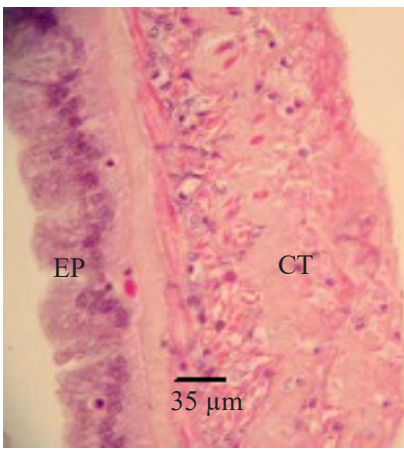

(i)

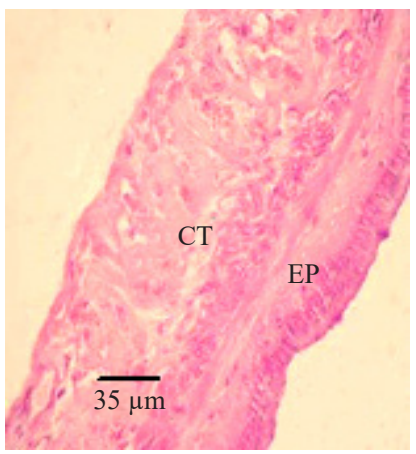

(b)

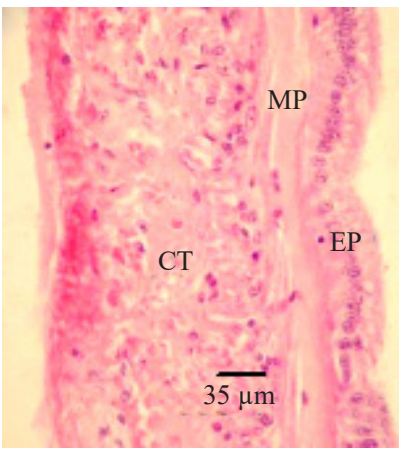

(f)

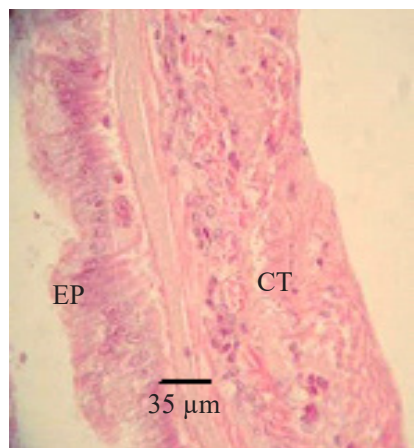

(j)

layer disintegrated, connective tissue fibres between muscle cells damaged and severe vacuolation was seen in the connective tissue (Fig. 2e).

After refeeding for 5 days, the digestive system in $\mathrm{S}_{5}$ group recovered. After 2 days refeeding, the height of the gut epithelial cells and the thickness of circular muscle layer increased in $\mathrm{S}_{10}$ group (Fig. 2f). In the same treatment group after 5 days refeeding, height of the epithelial cells and thickness of the circular

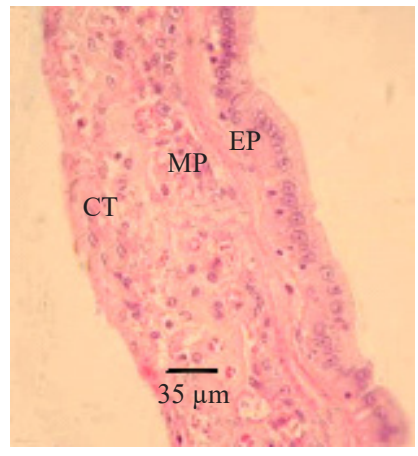

(c)

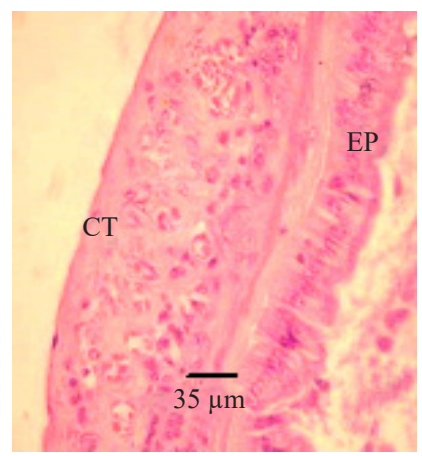

(g)

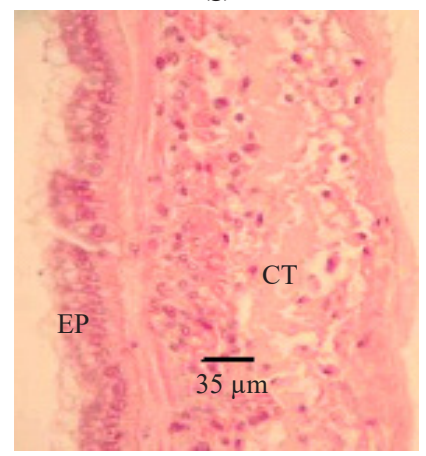

(k)

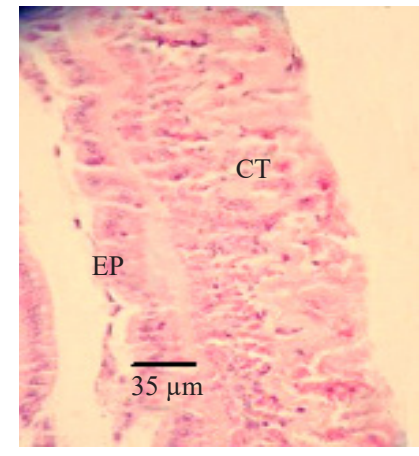

(d)

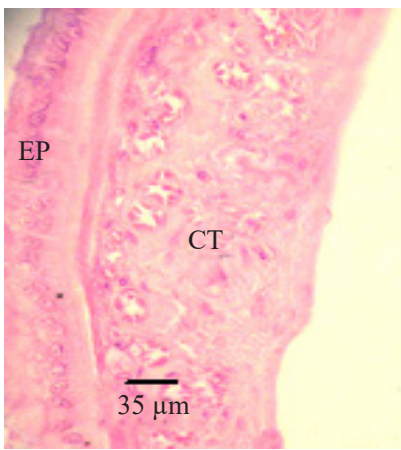

(h)

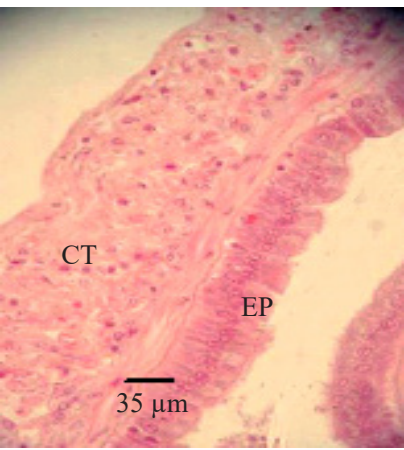

(1)

Fig. 2. Histological changes in the gut of control and starved $P$. japonicus

(a): Transverse section of gut in the control group $\left(\mathrm{S}_{0}\right)$ showing normal tissue architecture; (b): Epithelial cells showing reduced thickness in $\mathrm{S}_{5}$ group after 5 days of starvation; (c): Attenuated membrane propria of the gut in $\mathrm{S}_{10}$ group after 10 days starvation; (d): Loose connective tissue in the gut muscle tissue in $\mathrm{S}_{15}$ group after 15 days starvation; (e): Damaged epithelial cell boundary and fragmented connective tissue fibers in $\mathrm{S}_{25}$ group after 25 days starvation; (f): Height of the epithelial cells and thickness of the membrane propria increased after 2 days refeeding in $\mathrm{S}_{10}$ group; $(\mathrm{g})$ : Thickness of circular muscle layer increased after 5 days refeeding in $\mathrm{S}_{10}$ group; (h): Gut histological structure resembling control group after 10 days refeeding in $\mathrm{S}_{10}$ group; (i): Increased height of epithelial cells which are distributed unevenly after 2 days refeeding in $\mathrm{S}_{15}$ group; (j): Connective tissue organized evenly after 10 days refeeding in $\mathrm{S}_{15}$ group; $(\mathrm{k})$ : Distinct epithelial cells, while connective tissue still loose in $\mathrm{S}_{25}$ group after 2 days refeeding; (1): Height of epithelial cells increased and the cells arranged evenly in $\mathrm{S}_{25}$ group after 10 days refeeding. CT: Connective tissue; EP: Epithelial cell; MU: Muscle; MP: Membrane propria 
and longitudinal muscle layers gradually increased (Fig. 2g). After refeeding for 10 days, there was no significant difference in the height of epithelial cells in comparison with control group and the epithelial cells were found arranged evenly; also the cells of connective tissue and the longitudinal muscle cells increased, but arranged sparsely (Fig. 2h). After refeeding for 15 days, the structure was found similar as control group. In $\mathrm{S}_{15}$ group, after 2 days refeeding the height of the epithelial cells increased, but were arranged unevenly (Fig. 2i). The height of epithelial cells and the thickness of circular muscle as well as the number of longitudinal muscles gradually increased after 10 days refeeding, with the connective tissue in the chorion distributed evenly (Fig. 2j). After refeeding for 15 days, height of epithelial cells was back to the control group level, the thickness of circular muscle layer and the number of longitudinal muscle increased. In $\mathrm{S}_{25}$ group, the epithelial cells were clear with increased height and the connective tissue comparatively loosened after 2 days refeeding (Fig. 2-k). After 10 days refeeding, the height of epithelial cells increased with cells arranged evenly, thickness of the circular muscle layer increased, but the number of longitudinal muscle was low and the connective tissue was distributed evenly (Fig. 2-1). The eptithelial cells were found arranged closely after refeeding for 15 days and other structures were similar as control group, except for the significant difference in the height of cells.

The midgut gland of control group shrimps had the four types of cells (E, R, F and B cells) intact, with the boundary of the hepatic tubules clear, with clearly demarcated star shaped lumen. The E cell volume was small, with large round nucleus and with large number of zymogen granules. The number of $\mathrm{R}$ cells was highest in the midgut gland, with the nucleus located in the center of the cell and close to the base. Nucleus contained 1-2 nucleoli and multiple lipid droplets. The F cells were strong basophilic, with large round nucleus, having large nucleolus. The B cells have high volume with lipid droplets inside (Fig. 3a).

After 5 days starvation, the lumen of the hepatic tubules had floccules inside and there were no obvious changes in the R and F cells (Fig. 3b). After 10 days food deprivation, the connective tissue between the hepatic tubules became thin, the lumen enlarged losing the star shape. Number of R cells decreased, whereas the number of the F cells increased (Fig. 3c). After 15 days food deprivation, the shape of hepatic tubules became irregular and the number of cells decreased, part of the cells disassembled and sloughed off cells were visible inside the lumen. After 25 days of food deprivation, lumen size of hepatic tubules increased, with large number of sloughed cells in the cavity, and severe vacoulation in the tubular epithelium (Fig. 3e).

The midgut gland recovered nearly back to the control group stage after refeeding for 2 days in the 5 days food deprived group. After refeeding for 2 days in the $\mathrm{S}_{10}$ group, the connective tissue was thin between hepatic tubules, with big lumen and no floccules inside and number of B cells increased (Fig. 3-f). After refeeding for 10 days, the connective tissue became thick, lumen became small, number of $\mathrm{R}$ cells increased, whereas the number of $\mathrm{B}$ cells decreased. After refeeding for 15 days, the structure recovered to control group level. In the 15 days food deprived group, after refeeding for 2 days, connective tissue was found thin between hepatic tubules, part of the lumen of the hepatic tubules enalrged, with still presence of sloughed material and with increased number of B and R cells (Fig. 3g). After refeeding for 5 days, sloughed material were not seen in the lumen and the number of $\mathrm{R}$ cells increased. After refeeding for 10 days, the lumen was still large and the number of lipid droplets was larger inside the B cells. After refeeding for 15 days, the area of acini hepatis was enlarged, whereas the lumen became small. The number of B cells decreased, whereas the number of $\mathrm{R}$ cells increased, almost reaching to the level of control group. After 2 days refeeding in the $\mathrm{S}_{25}$ group, the $\mathrm{F}$ and $\mathrm{B}$ cells increased in number close to the inner membrane layer and regained the star shape of the lumen. Also, the nucleus of the B cells was squeezed by lipid droplet. (Fig. 3h). After refeeding for 5 days, the area of acini hepatis increased, the hepatic tubules distributed unevenly, the number of the $\mathrm{R}$ cell increased with lipid droplets inside B cells. After refeeding for 10 days, connective tissue increased between hepatic tubules, the number of the R cells increased, whereas the number of B cells decreased with lipid droplets inside. After refeeding for 15 days, the hepatic tubular epithelial cells were distributed unevenly, with number of $\mathrm{F}$ and $\mathrm{B}$ cells more than that in R cells, but still did not resume the structure of control group (Fig. 3i).

In crustaceans, midgut gland is an important digestive organ as it influences the synthesis and secretion of the digestive enzyme and the absorption of nutrients, also it affects the storage of the inorganic material and the metabolism of lipid and sugar. Moreover, HSI could be used as a health indicator in the animals. Under feeding and food limitation conditions, the stored nutrients of the midgut gland could be used for generating energy, leading to decrease in the HSI. In the present study, significant difference was observed in HSI in $\mathrm{S}_{5}$ group after 5 days of food deprivation, in comparison with control group. However, after refeeding for 15 days, the hepato-somatic index in the $\mathrm{S}_{5}, \mathrm{~S}_{10}$ and $\mathrm{S}_{15}$ groups were 


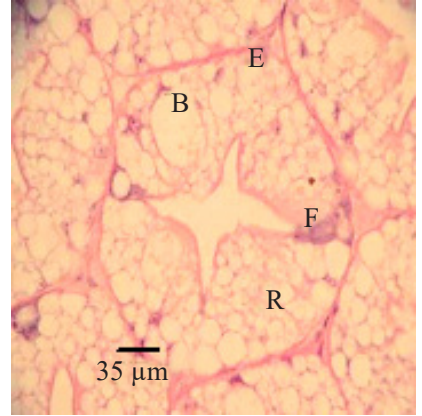

(a)

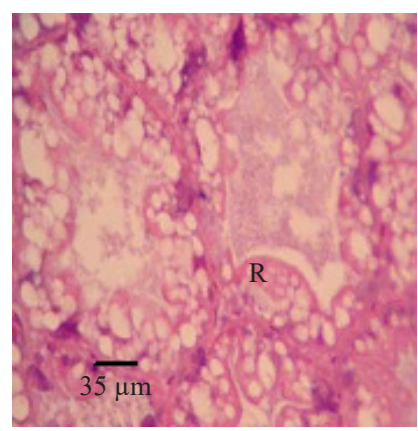

(d)

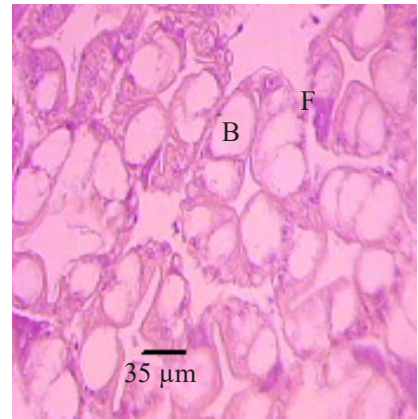

(g)

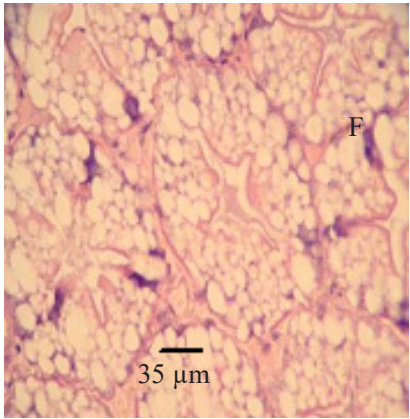

(b)

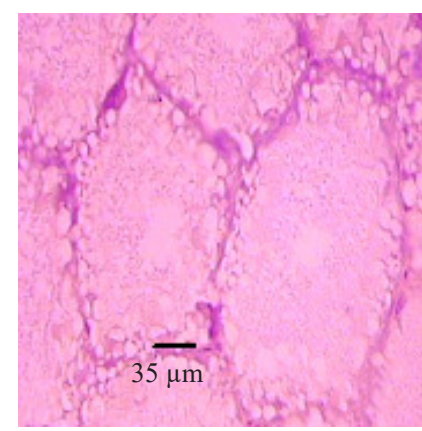

(e)

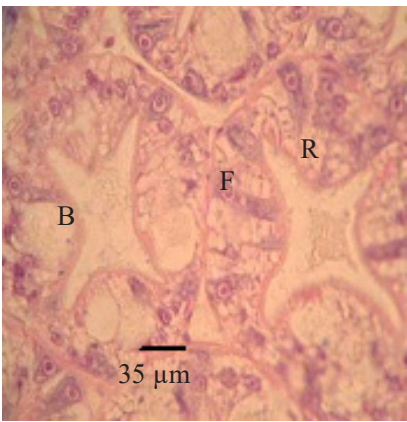

(h)

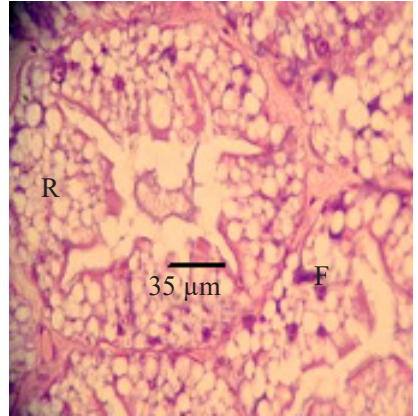

(c)

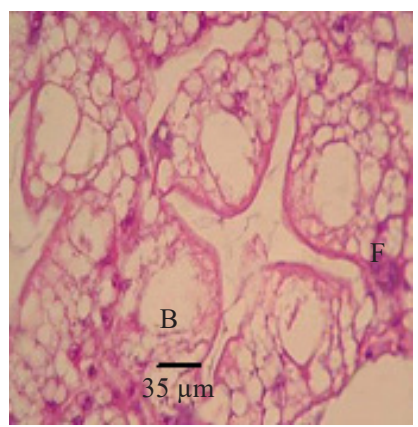

(f)

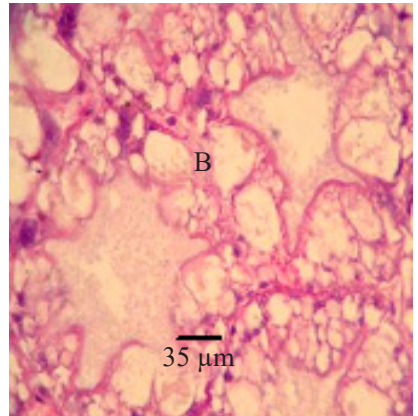

(i)

Fig. 3. Histological structure of midgut gland in the experimental and control groups of P. japonicus

(a): Midgut section of control group $\left(\mathrm{S}_{0}\right)$ showing normal architecture; (b): Increased number of $\mathrm{F}$ cells in $\mathrm{S}_{5}$ group after starvation for 5 days; (c): Damaged cell structure and decreased number of $\mathrm{R}$ cells in $\mathrm{S}_{10}$ group after 10 days starvation; (d): $\mathrm{R}$ cells further decreased and part of cells disassembled in $\mathrm{S}_{15}$ group after 15 days of starvation; (e): most of the cells disassembled and with very little cells in the inside layer of the membrane in $\mathrm{S}_{25}$ group after 25 days starvation; (f): Number of B cells increased after refeeding for 2 days in $\mathrm{S}_{10}$ group; ( $\mathrm{g}$ ): Number of $\mathrm{B}$ cells increased after refeeding for 2 days in $\mathrm{S}_{15}$ group; (h): F and B cells larger and R cells smaller, but both not attained control group level after refeeding for 2 days in $\mathrm{S}_{25}$ group; (i): Increased number of $\mathrm{B}$ and R cells after refeeding for 15 days in $\mathrm{S}_{25}$ group. E: Embryonic cell; R: Absorptive cell; B: Secretory cell; F: Fibre cell

back to the control group level, and only $\mathrm{S}_{25}$ group had significant difference with the control group. Therefore, it could be inferred that the hepato-somatic index is a sensitive index to evaluate the nutritional condition in $P$. japonicus. Histological examination is an effective method to evaluate nutritional condition in an animals. Several workers have focused on the examination of histological changes in the digestive tract in response to starvation, in fishes, like Silurus meridionalis and Sciaenops ocellatus (Zhang and Xie, 2000; Shan et al., 2008). Their results clearly show that, starvation led to decrease in thickness of the wall of digestive tract, and also had influence on the secretory granules to some extent. In Paralichthys dentatus Bishal and Bengtson (1995), observed that histological index was the best indicator for assessing fish nutritional condition, as the method is reliable, simple and sensitive and suggested that the intestinal epithelial cell height and mucosal thickness could be effectively used as indicator for evaluating fish nutritional condition.

There is very little information available on the structural changes of digestive tract after starvation and refeeding in crustaceans. In this study, starvation 
had significant influence on the stomach, intestine and midgut gland of P. japonicus. The structural changes in the stomach and intestine were similar. The height of epithelial cells decreased, distributed unevenly, boundary unclear until cell shedding, fibres fragmented in the connective tissue and distributed unevenly with large gaps and vacuolation with increase in duration of starvation. The influence of starvation on the structure of the midgut gland tissue showed no structural integrity of the hepatic tubule, and the lumen, F cells increased and number of $\mathrm{R}$ cells decreased. These results indicated that the animals ustilised the material for metabolism from the digestive tract and midgut gland during the starvation period. After refeeding, the morphology of the epithelium and the structure of the connective tissue were regained, except in the $\mathrm{S}_{25}$ group.

The structure of the midgut gland recovered faster after refeeding. During the early periods of recovery, the number of B cells increased, whereas F cells decreased. Towards later stages, the number of $\mathrm{R}$ cells significantly increased with decrease in B and F cells. This clearly shows that the $\mathrm{B}, \mathrm{F}$ and $\mathrm{R}$ cells have different functions. The physiological function, such as shrimp growth, can be directly affected by the damage/recovery of the structures in stomach, intestine and midgut gland. Li et al. (2002) compared the structural changes of the digestive organ and growth in $S$. ocellatus after starvation and refeeding and found out that the recovery of digestive tract structures and the compensatory growth were similar. When the tissue structures regained to the normal level, compensatory growth began. Cheng et al. (2000) examined the ultrastructure of hepatopancreas to analyse the nutritional condition in Eriocheir sinensis and found that the structure and function of the digestive organ were supplementary to each other. In the present study, the damage to the structures were minimal when starved for 5 days and the digestive function resumed quickly during refeeding. Therefore, at the end of the experiment, weight in the $\mathrm{S}_{5}$ group was higher than that of the control group. In $\mathrm{S}_{10}$ group, the structure basically regained to normal level and the weight was similar as control group. In $\mathrm{S}_{15}$ group, though the structure basically recovered to normal, weight was not similar to control. When the refeeding period extended, the weight regained similar to that of control group. The histological structure of the digestive tract in the $\mathrm{S}_{25}$ group also recovered, but it needed longer time for recovery due to the extended duration of starvation.
The present study evaluated the effect of food deprivation on the structural changes of digestive system in juvenile $P$. japonicus. Results from the present study indicate that short term food deprivation $(<15$-days $)$ has less impact on the digestive system of $P$. japonicus, whereas long term food deprivation ( $>25$-days) can cause severe damage to the digestive tract.

\section{References}

Bisbal, G. A. and Bengtson, D. A. 1995. Development of the digestive tract in larval summer flounder. Fish Biol., 47: 277-291.

Dall, W., Hill, B. J., Rothlisberg, P. C. and Sharples, D. J. 1990. Moulting and growth. In: Blaxter, J. H. S. and Southward, A. J. (Eds.), The biology of the penaeidae. Academic Press, London, UK, p. 213-250.

Cheng, Y., Du, N. and Lai, W. 2000. Ultrasturcutre of the hepatopancreatic R and F cells and lipid storage in the Chinese crab (Eriocheir sinensis). Acta Zool. Sinica. 46: 8-13.

Li, X., Jiang, Z., Tan, X. and Jia, Z. 2002. Effects of starvation and refeeding on histology of digestive system in Sciaenops ocellatus. J. Fish. Sci. China, 9: 211-214.

Liu, M. and Li, C. 2012. Histopathological observation of rotten cockroach and bubble disease in juvenile hybrid carp. Hebei Fish., 3:28-31.

Phlippen, M. K., Webster, S. G., Chung, J. S. and Dircksen, H. 2000. Ecdysis of decapod crustaceans is associated with a dramatic release of crustacean cardioactive peptide into the haemolymph. J. Exp. Biol., 203: 521-536.

Sacristan, H. J., Ansaldo, M., Franco-Tadic, L. M., Gilmenez, A. V. F. and Greco, L. S. L. 2016. Long-term starvation and posterior feeding effects on biochemical and physiological responses of midgut gland of Cherax quadricarinatus juveniles (Parastacidae). PLoS ONE 11, e0150854.

Sanchez-Paz, A., Garcia-Carreno, F., Muhlia-Almazan, A., Peregrino-Uriarte, A. B., Hernandez-Lopez, J. and Yepiz-Plascencia, G. 2006. Usage of energy reserves in crustaceans during starvation: status and future directions. Insect Biochem. Mol. Biol., 36: 241-249. DOI: 10.1016/j. ibmb.2006.01.002.

Shan, X., Cao, L., Huang W. and Sou, S. 2009. Feeding, morphological changes and allometric growth during starvation in miiuy croaker larvae. Envir. Biol. Fish., $86: 121$

Zhang, B. and Xie, X. 2000. Starvation metabolism in the southern catfish (Silurus meridionalis). Oceanol et Limnol. Sinica, 31: 480-484. 